\title{
Gold induced enterocolitis complicated by cytomegalovirus infection: a previously unrecognised association
}

Academic Unit of

Medicine, St James's University Hospital, Leeds

$\mathrm{V}$ Wong

P Howdle

Department of Histopathology, St James's University Hospital, Leeds $\mathrm{J}$ Wyatt

Academic Unit of Pathology, University of Leeds, Leeds F Lewis

Correspondence to: Dr P Howdle, Academic Unit of Medicine, St James's University Hospital, Leeds LS9 7TF.

Accepted for publication 20 October 1992

V Wong, J Wyatt, F Lewis, P Howdle

Enterocolitis is a rare complication of treatment with gold salts. It was first described in 1935 by Goldhammer ${ }^{2}$ and since then only 21 cases have been described..$^{2-417}$ The mechanism is unclear. An appreciable proportion of these cases was associated with high morbidity and mortality. ${ }^{4811}$ Different treatment regimes including intensive supportive care with a combination of antibiotics, steroids, dimercaprol, and disodium cromoglycate have produced variable success. ${ }^{571315}$ No other concomitant infective agents have been implicated in the course of the disease to date. We report a case of gold induced enterocolitis complicated by cytomegalovirus (CMV) infection that responded to treatment with intravenous gangcyclovir.

\section{Case report}

A 44 year old housewife with severe seropositive rheumatoid arthritis was unresponsive to treatment with simple analgesia, non-steroidal anti-inflammatory agents (NSAIDS), hydroxychloroquine, D-penicillamine, and salazopyrine. Gold treatment was therefore commenced. She was given a test dose of $10 \mathrm{mg}$ intramuscular gold (myocrisin) with no major side effects. Fortnightly intramuscular injections of $50 \mathrm{mg}$ mycocrisin were administered over the next three months. She developed a mild watery diarrhoea after two months of treatment but this resolved after gold injections were temporarily stopped. Further gold treatment was recommenced two weeks later and she received a total dose of $372.5 \mathrm{mg}$. Her rheumatoid disease activity responded well clinically. Unfortunately two weeks after her last gold injection she presented acutely complaining of lethargy, anorexia, weight loss $(9.5 \mathrm{~kg})$, abdominal pain, and watery diarrhoea (up to 20 times per day) with a small amount of blood. She was admitted immediately and no further gold treatment was given. She was not taking any other medication. She or the family had no history of colitis. She also had a three to four week history of a productive cough with greenish sputum.

On examination she was unwell with a pyrexia at $38^{\circ} \mathrm{C}$, a tachycardia, and chest signs consistent with a left basal pneumonia. Her rheumatoid arthritis was quiescent and remained so throughout her hospital admission. Her abdomen was generally tender and rectal examination showed watery stool stained with mucus and a small amount of blood. Rigid sigmoidoscopy showed pronounced diffuse inflammation with multiple superficial ulceration and a biopsy confirmed severe proctitis (Fig 1). She showed some response to treatment with supportive measures
- namely, oral $20 \mathrm{mg}$ prednisolone daily in a reducing dose and ampicillin. There was a reduction in her stool frequency, an improvement in her abdominal pain, and a less productive cough. She was discharged after one week but four weeks later, she relapsed with symptoms of watery diarrhoea and fresh blood, abdominal pain, and a further weight loss of 6.3 kg. Also, her productive cough had persisted. Her only medication was dihydrocodeine. On examination she was moribund and dehydrated. She was apyrexial and a maculopapular rash was present on her arms. Chest examination showed left basal crepitations and her abdomen was diffusely tender but bowel sounds were present. Moderate peripheral leg oedema was also noted.

\section{INVESTIGATIONS}

Full blood count showed $12 \cdot 2 \mathrm{~g} / 100 \mathrm{ml}$ haemoglobin, white cell count, $11.3 \times 10^{\%} / 1$ with $89 \%$ neutrophils and no eosinophils, and platelet count $410 \times 10^{9} / 1$. C-reactive protein concentration was $75 \mathrm{mg} / \mathrm{l}$ (normal $<10 \mathrm{mg} / \mathrm{l}$ ). Urea and electrolytes gave a $121 \mathrm{mmol} / 1$ serum sodium, 5.6 $\mathrm{mmol} / \mathrm{l}$ potassium, $5.6 \mathrm{mmol} / \mathrm{l}$ urea, and 96 umol/l creatinine. Liver function tests showed normal bilirubin and transaminases but raised alkaline phosphatase at $1062 \mathrm{IU} / 1$ (normal $<300$ $\mathrm{IU} / \mathrm{l})$. Serum albumin concentration was $22 \mathrm{~g} / \mathrm{l}$. Urinalysis showed proteinuria and 24 hour urinary protein concentration was $0.4 \mathrm{~g} / \mathrm{l}$. A chest $x$ ray film showed left basal shadowing consistent with infection and an abdominal $x$ ray

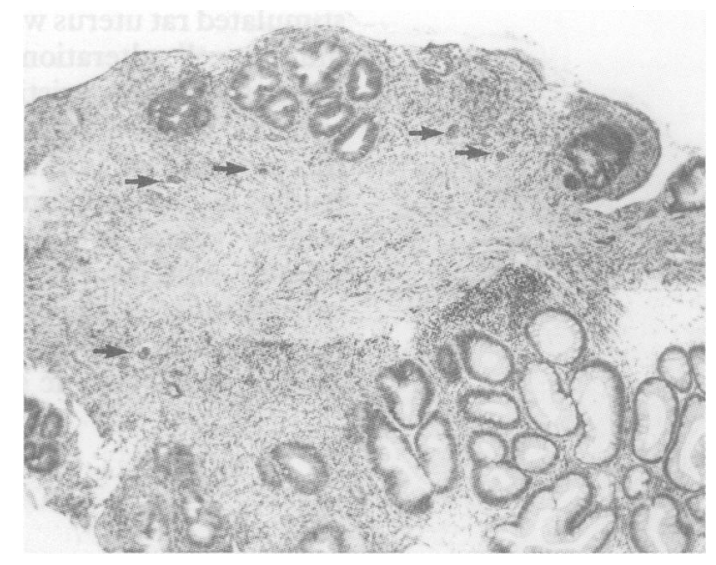

Figure 1: Low power view of initial rectal biopsy. There is pronounced variability in the severity of proctitis with total destruction of glands in some areas and very distorted glandular architecture with regenerative atypia in others. Clumps of endocrine cells mark the previous position of mucosa glands (arrows). Haematoxylin and eosin; original magnification $\times 14$. 

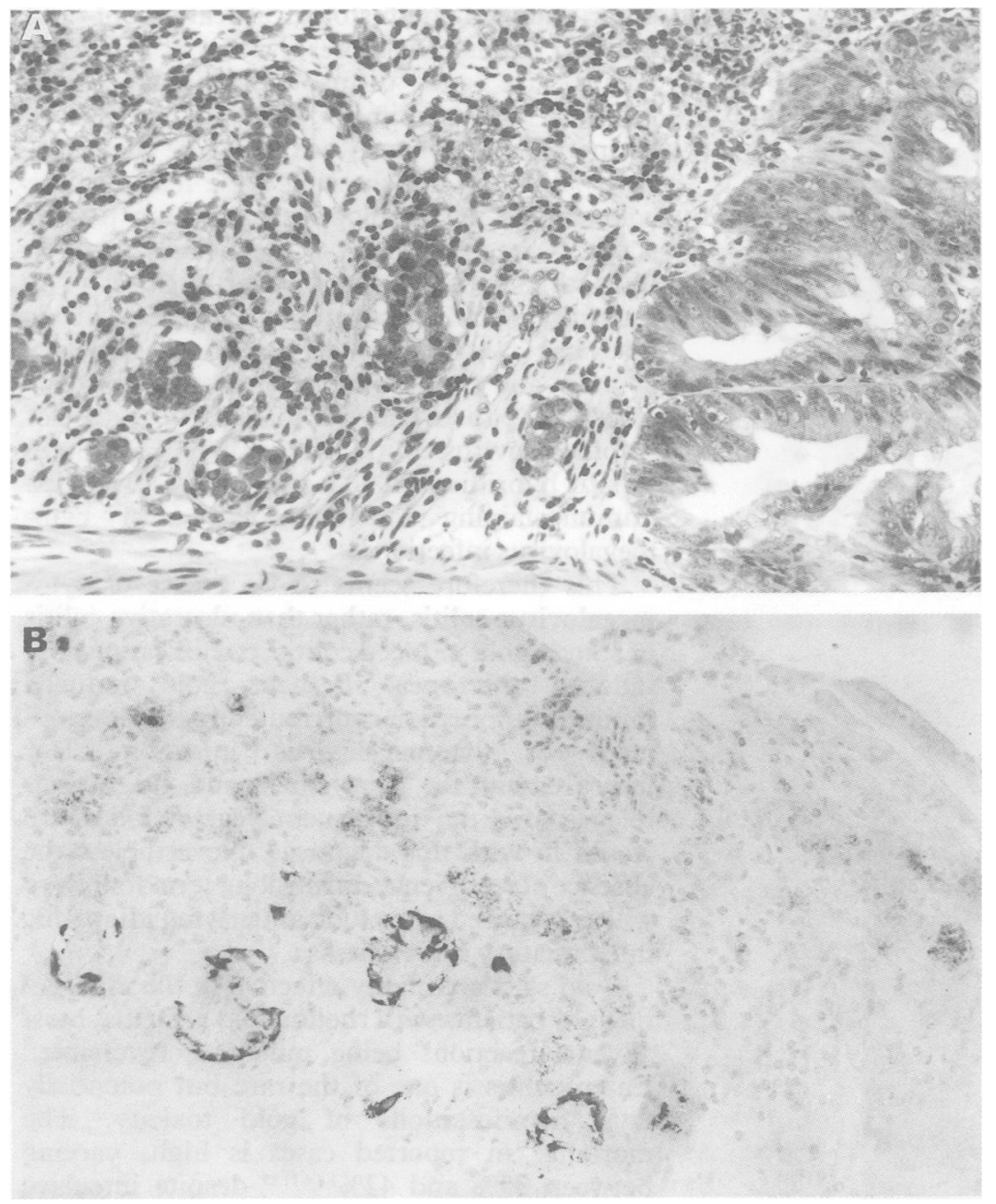

Figure 2: (A) Colonic mucosa from colonoscopic biopsy. The group of glands on the right show pronounced regenerative atypia of the epithelium with continuing cell death by apoptosis. To the left, groups of endocrine cells indicate the previous position of destroyed crypts. Haematoxylin and eosin; original magnification $\times 120$.

(B) Adjacent section to Figure 2A, stained by Grimelius confirming hyperplasia of neuroendocrine cells and crypt bases. temperature settled. Unfortunately, this was complicated by the development of a left lung abscess on the fourth week that required radiological drainage under ultrasonographic guidance. Fibreoptic bronchoscopy was performed and revealed no obstructive bronchial lesion. In view of her deteriorating clinical condition and colonoscopic biopsy findings suggesting cytomegalovirus infection, prednisolone was withdrawn and she was treated with a course of intravenous gangcyclovir (500 mg daily) for two weeks. Her diarrhoea decreased with improved appetite and weight gain, a rising serum albumin, and resolution of her peripheral oedema. Her serum alkaline phosphatase fell to normal. Further results showed that her immunoglobulins were low, particularly IgG with a value of $5 \cdot 11 \mathrm{~g} / 1$, and she was given intravenous immunoglobulin (Gammimmune$\mathrm{N}, 25 \mathrm{~g}$ ) to aid her recovery. Subsequent investigations showed this to be a transient deficiency attributed to gold and her immunoglobulins returned to normal (IgG 10.6 g/l) with no further treatment. Cellular immune function was normal. A repeat flexible sigmoidoscopy showed improvement in her proctocolitis and the histological features showed resolving colitis. She was discharged home after seven weeks in hospital. Further colonoscopy after three and seven months showed improvement to normal appearance. She remained well clinically to follow up at one year after onset of her colitic symptoms.

\section{HISTOLOGY}

Initial rectal biopsy and subsequent ileal and colonic biopsies at colonoscopy before treatment all showed similar features (Figs 1 and 2). There was a severe proctocolitis and ileitis with glandula distortion and surface ulceration. This was variable with some biopsies showing very florid regenerative features (Fig 2A). Eosinophils were not evident in the inflammatory cell infiltrate. A prominent feature was the surviving aggregates of endocrine cells marking the former position of glandular bases where colonic crypts had been destroyed (Fig 2B), a feature characteristically seen in graft $v$ host disease. Also, apoptotic degeneration was frequent within epithelial cells of remaining crypts further increasing the similarity to graft $v$ host disease. Occasional inclusion bodies highly suggestive of cytomegalovirus were seen in the ileal and rectal biopsies at colonoscopy and subsequently on the initial rectal biopsy when more sections were examined. Although immunoperoxidase was negative, these inclusions were confirmed as containing cytomegalovirus by DNA in situ hybridisation (Fig 3).

The colonoscopic biopsies at seven weeks (on discharge from hospital), three, and seven months showed a progressive improvement in the proctocolitis although a degree of glandular distortion has persisted throughout. No viral inclusion bodies were seen in biopsies taken after treatment with gangcyclovir. worsening productive cough with dirty green sputum during her second week in hospital. Sputum culture grew Pseudomonas aeroginosa that was sensitive to ciprofloxacin. With a combination of intravenous ciprofloxacin and physiotherapy her condition improved and her

\section{Discussion}

This patient developed a severe debilitating 

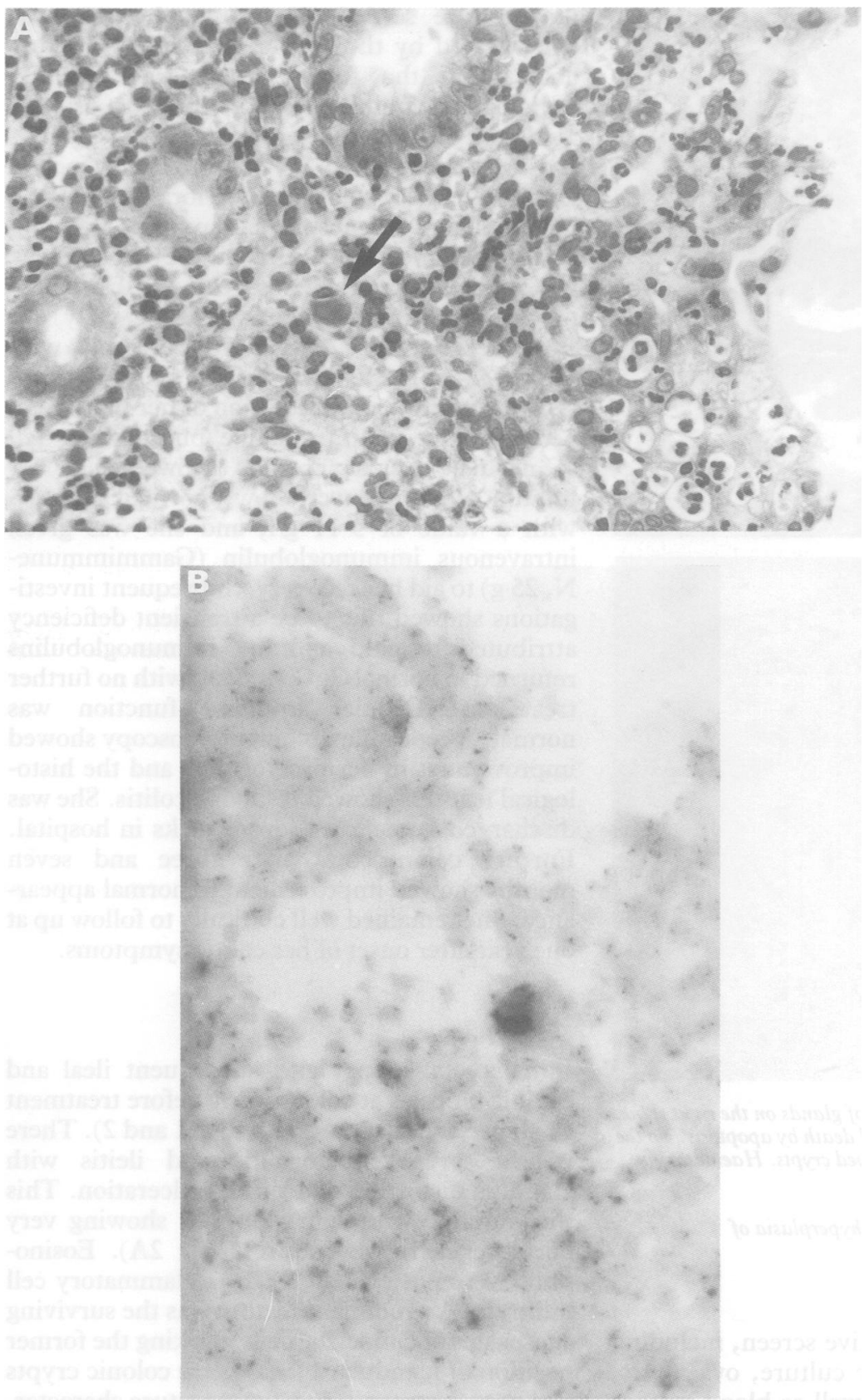

Figure 3: (A) Terminal ileal biopsy showing florid acute on chronic inflammation with mucin depletion and some cell loss within the crypts. An enlarged cell in the lamina propria shows nuclear and cytoplasmic inclusions suggestive of cytomegalovirus infection (arrows). Haematoxylin and eosin; original magnification $\times 120$.

(B) A rectal biopsy from the same series as Figure $3 A$ in which the inclusion material in the cytoplasm and nucleus is labelled positively by DNA in situ hybridisation. This technique involves cloning $a 21 \mathrm{~Kb}$ Hind III fragment of CMV into pAT153 and biotinylated by nick translation with biotin-11-dUTP. This biotinyulated probe (75 $\mu$ l at a concentration of $200 \mathrm{ng} /$ $\mathrm{ml}$ ) in hybridisation buffer was applied to pretreated sections and hybridised overnight at $37^{\circ} \mathrm{C}$. The hybridisation signal was detected with a biotinstreptavidin alkaline phosphatase sandwich technique as described previously. ${ }^{22}$

colitis with mainly watery diarrhoea two weeks after stopping a course of parenteral gold treatment with a total dosage of $372.5 \mathrm{mg}$. The close temporal relation of initial resolution of her watery diarrhoea on stopping her gold treatment and subsequent development of severe enterocolitis on recommencement taken together with the renal (proteinuria), and skin (maculopapular rash) involvement as well as transient hypo- $\gamma$-globulinaemia suggested gold as the primary cause of her colitis. There are few descriptions of the histological features of gold induced colitis, but a preservation of glandular architecture and diffuse inflammatory cell infiltrate $^{11 \text { Is }}$ sometimes with a prominent eosinophil component ${ }^{73}$ are said to be characteristic. Although not showing these features, the colonic and rectal biopsies from our patient showed changes unlike those usually seen in idiopathic inflammatory bowel disease. The striking resemblance to graft $v$ host disease in our case has been described in cytomegalovirus colitis $^{19}$ and its occurrence here in a nontransplant patient shows it to be a true feature of cytomegalovirus colitis. Like others, ${ }^{20}$ we found in situ hybridisation to be more sensitive than immunostaining for confirmation of cytomegalovirus infection.

This therefore seems to be a case of cytomegalovirus colitis, rather than ulcerative colitis or simple gold induced colitis, complicating gold induced diarrhoea. Perhaps gold induced immunosuppression contributed to the development of cytomegalovirus infection. Her improvement on gancyclovir and no further relapse over the subsequent year of follow up would fit with this diagnosis. Nevertheless the absence of recurrence during long term follow up will be required to exclude underlying idiopathic inflammatory bowel disease.

Gold salts are highly effective in the management of patients with rheumatoid arthritis, most adverse reactions being mild and reversible. ${ }^{1}$ Enterocolitis is one of the rare but potentially fatal manifestations of gold toxicity. The mortality in reported cases is high, varying between $35 \%$ and $42 \%^{14611}$ is despite intensive supportive treatment in conjunction with the use of antibiotics, steroids, and dimercaprol. There was a reported case of gold induced eosinophilic colitis responding to sodium cromoglycate. ${ }^{13}$ Of the survivors, none suffered recurrent symptoms after complete recovery. None was rechallenged with gold. The precise mechanism of gold induced enterocolitis is uncertain but seems to be an allergic reaction to elemental gold as various gold salt preparations have been implicated. All patients except one were women, aged between 24 and 59 years, who received low total doses of gold salts $(74-485 \mathrm{mg})$ before recognition of enterocolitis. Any site in the gastrointestinal tract can be affected, although the colon is the commonest and two cases of colonic perforation necessitating colectomy have been described. ${ }^{11}$ Patients with gold induced colitis have diarrhoea as a constant feature. This is usually severe and watery, often bloody, and can last up to three or four months. Other features include fever, nausea, vomiting, abdominal cramps, and, less commonly, skin rashes. ${ }^{19}$ Repeated stool cultures for pathogens and parasites are invariably negative. This, as far as we know, is the first reported case of the combination of gold induced and infective colitis.

In view of the extreme severity of gold induced colitis, the diagnosis should be considered in any patients on gold treatment who present with diarrhoea, particularly bloody diarrhoea as in our case. Also, concomitant cytomegalovirus infection should be borne in mind in such circumstances. 
We thank Dr Michael Martin, consultant rheumatologist, St James's University Hospital, Leeds, for his kind permission to report this interesting case.

1 Gibbons RB. Complications of chrysotherapy; a review of recent studies. Arch Intern Med 1979; 139: 343-6.

2 Goldhammer S. A fatal case of solganol poisoning. Med Klin $1935 ; 645-47$

3 Perry MW. Gold injections and colitis. FAMA 1939; 113: 965.

4 Anderson NL, Palmer WL. Danger of gold salt therapy. Report of a fatal case. FAMA 1940;115: 1627-30.

5 Kandrac M, Pav J, Pechova I. Successful steroid therapy of severe enteritis caused by gold therapy. Cas Lek Cesk 1961; 100: $361-7$.

6 Roe M, Sears AD, Arndt JH. Gold reaction panenteritis. A case report with radiologic findings. Radiology 1972; 104

7 Kaplinsky N, Pras M, Frankl O. Severe enterocolitis complicating chrysotherapy. Ann Rheum Dis 1973; 32: 574-7.

8 Siegman-Igra Y, Yaron M, Siletzki M, Schiman E, Gilat T. Colitis and death following gold therapy. Rheumatology and Rehabilitation 1976; 15: 245-7.

9 Stein HB, Urowitz MB. Gold-induced enterocolitis. Case report and literature review. 7 Rheumatol $1976 ; 3: 21-6$.

10 Szpak MW, Johson RC, Brady CE, Boswell RN. Gold (A) induced enterocolitis [abstract]. Gastroenterology 1979; 76: 1257

11 Fam AG, Paton TW, Shamess CJ, Lewiss AJ. Fulminan colitis complicating gold therapy $\mathcal{F}$ Rheumatol 1980; 7:479

12 Huston GJ. Gold colitis, therapy and confirmation of mucosal recovery by measurement of rectal potential difference. Postgrad Med F 1980; 56: 875-7.

13 Martin DM, Goldman JA, Gilliam J, Nasrallah SM. Goldinduced eosinophilic enterocolitis: Response to oral cromolyn sodium. Gastroenterology 1981; 80: 1567-70.

14 Sukenik S, Hirsh M, Yanai-inbar I, Krawiez, Freund B Horowitz. Enterocolitis complicating chrysotherapy: Case report and review of the lierature. Israel $\mathcal{F} \mathrm{Med} S c i$ 1982; 18: $1040-3$.

15 Eaves R, Hansky J, Wallis P. Gold-induced enterocolitis: Cas report and a review of the literature. Aust $N Z \mathcal{Z}$ Med 1982, 12: $617-20$

16 Nagler J, Paget A. Non-exudative diarrhoea after gold salt therapy: Case report and review of the literature. $A m \mathcal{F}$ Gastroenterol 1983; 78: 12-4.

17 White RF, Major AC Gold colitis. Med f Aust 1983; 1: 174-5. 18 McCormick PA, O'Donoghue D, Lemas B. Gold-induced colitis: Case report and literature review. Ir Med F 1985; 78: colitis:

19 Snover CS. Mucosal damage simulating acute graft-versushost reaction in cytomegalus colitis. Transplantation 1984 39: $669-70$

20 Robey SS, Gage WR, Khajda FP. Comparison of immunoperoxidase and DNA in-situ hybridisation techniques in the diagnosis of cytomegalovirus colitis. Am F Clin Pathol 1988; 89: 666-71

21 Berk T, Gordon SJ, Choi HY, Cooper HS. Cytomegalovirus infection of the colon: A possible role in exacerbations of inflammatory bowel disease. Am F Gastroenterol 1985; 80: 355-60.

22 Lewis FA, Griffiths S, Dunnicliff N, Dudding N, Wells $M$ Bird CC. Sensitive in-situ hybridisation technique employing biotin-streptavidin-polyalkaline-phosphatase. $\mathcal{F}$ Clin Pathol 1987; 40: 163-6. 